\title{
Potential redox-sensitive Akt activation by dopamine activates Bad and promotes cell death in melanocytes
}

\author{
Hye-Ryung Choi,, Jung-Won Shin, ${ }^{\dagger}$ Hyun-Kyoung Lee, Jin-Young Kim, Chang-Hun Huh, Sang-Woong Youn \\ and Kyoung Chan Park*
}

Department of Dermatology; Seoul National University College of Medicine; Yeongeon-dong Jongno-gu; Seoul, Republic of Korea

'These authors contributed equally to this work.

Key words: Akt, dopamine, N-Acetyl-L-cysteine, bad, melanocyte

\begin{abstract}
Dopamine (DA) is a well known oxidative neurotoxin. In addition, Akt has been reported to deliver a survival signal that inhibits apoptosis. However, it has also been reported that chronic Akt activation leads to apoptosis in response to oxidative stress. The objective of the present study was to investigate the possible role of the Akt pathway in vitiligo and its possible relationship with DA-induced cell death using Mel-Ab cells. Cultured Mel-Ab cells were treated with DA with and without N-Acetyl-L-cysteine (NAC), which is known to have antioxidative properties. Cell viability was then assessed by a crystal violet assay and Annexin staining was performed. The changes in the expression of Akt were analyzed by western blot analysis. The cell viability was reduced by approximately $60 \%$ in response to treatment with $500 \mu \mathrm{M} D A$, and NAC effectively prevented this cytotoxic effect. Likewise, treatment with DA produced numerous Annexin positive cells, while treatment with NAC prevented this apoptotic cell death. Akt was slowly phosphorylated after treatment with DA, while NAC clearly inhibited the DA-induced Akt activation. Western blot analysis also showed that treatment with DA induced the activation of Bad. Finally, LY294002 exerted a protective effect against DA-induced apoptotic cell death. DA may induce redox-sensitive Akt activation and increase the level of Bad, which can promote cell death by heterodimerization with survival proteins. Moreover, NAC effectively protects against DA-induced melanocyte death via inhibition of DA-induced Akt activation.
\end{abstract}

\section{Introduction}

Oxidative stress has been implicated in the pathophysiology of multiple human diseases. ${ }^{1}$ Furthermore, oxidative stress is regarded as a mediator of nerve cell death in several neurodegenerative disorders. $^{2}$

Vitiligo is characterized by the selective destruction of melanocytes which had been derived from neuroectoderm. Although its cause is unknown, several reasons for the selective destruction of melanocytes have been suggested. Dopamine (DA) is a wellknown neurotoxin that plays an etiologic role in neurodegenerative disorders such as Parkinson's disease, and it has been reported that DA induces oxidative stress and neuronal cell death. ${ }^{3,4}$ Neural factors have long been suspected to contribute to the development of vitiligo, and catecholamines such as norepinephrine, epinephrine, and DA and their metabolites have been found to be elevated in the urine and plasma of vitiligo patients. ${ }^{5-7}$ We previously reported that melanocytes were susceptible to DA, and that thiol compounds such as $\mathrm{N}$-acetyl-L-cysteine (NAC) effectively protected against DA-induced melanocyte cell death. ${ }^{8}$ Using this model, the role of Akt in DA-induced cell death was investigated.
Activation of Akt is known to deliver a survival signal that inhibits apoptosis. ' It has also been reported that Akt inhibits apoptosis through a variety of molecular mechanisms, including direct phosphorylation and inhibition of the pro-apoptotic $\mathrm{Bcl}-2$ family and Bad. ${ }^{10}$ However, chronic Akt activation has also been reported to lead to apoptosis through oxidative stress. ${ }^{11}$ In this study, the mouse-derived spontaneously immortalized melanocyte cell line, Mel-Ab, was used to investigate the possible role that Akt pathway in vitiligo. ${ }^{12}$

\section{Results}

Dopamine-induced cytotoxicity and the effects of NAC. Mel-Ab cells were treated with various concentrations of DA $(0-500 \mu \mathrm{M})$ for $24 \mathrm{hr}$, after which the cell viability was measured. The cell viability was reduced by approximately $60 \%$ in response to treatment with $500 \mu \mathrm{M} \mathrm{DA}$; therefore, this concentration was chosen for further experiments (Fig. 1A). It was previously reported that NAC and glutathione protected Mel-Ab cells against dopamine-induced cell death. 8 Thus, the protective effects of NAC were evaluated. The results revealed that NAC effectively 


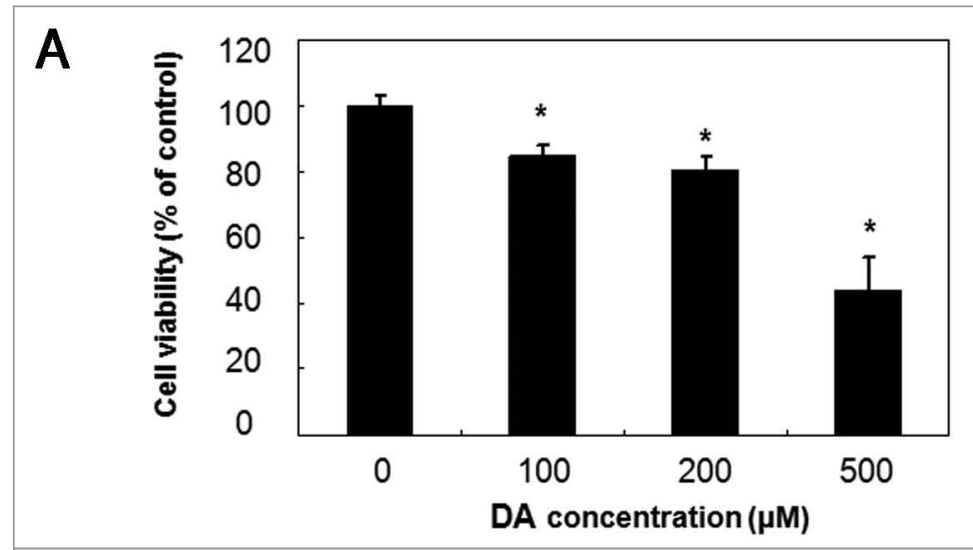

B

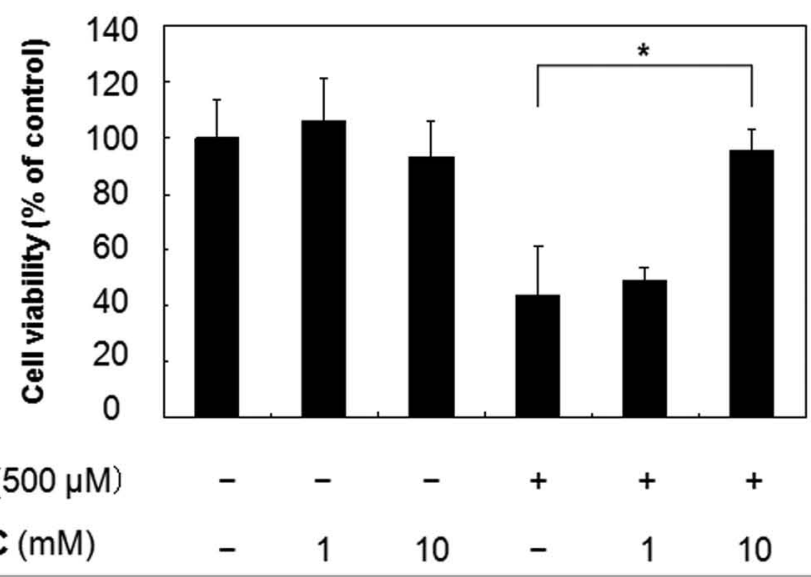

C

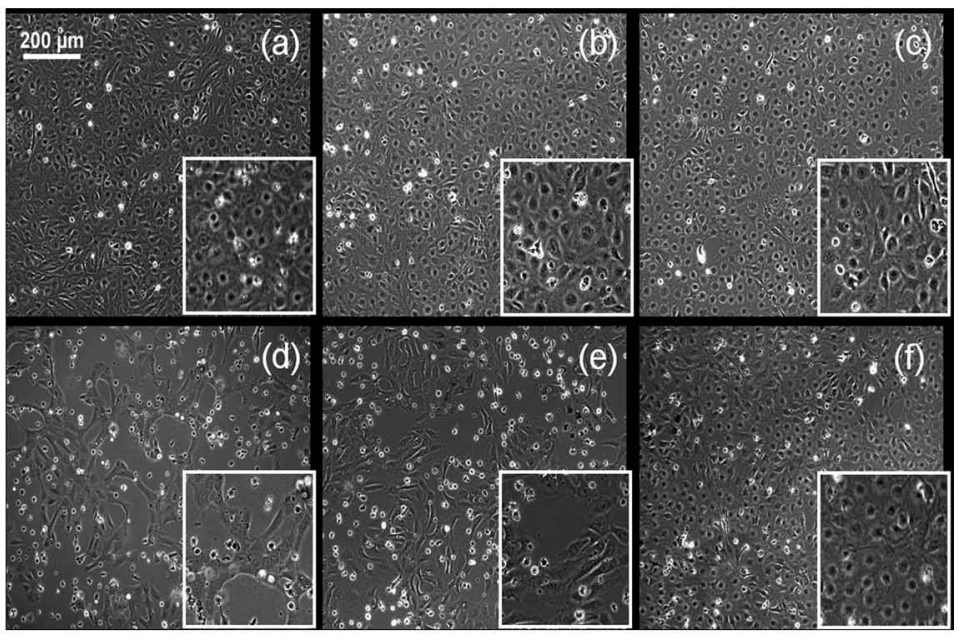

Figure 1. Concentration-dependent cytotoxic effects of DA and protective effects of NAC against DA-induced cytotoxicity. (A) Following serum starvation, the cells were treated with various concentrations of DA for $24 \mathrm{hr}$, after which their viability was measured by crystal violet assay. (B) After serum starvation, the cells were pretreated with different concentrations of NAC for $20 \mathrm{~min}$ and then treated with 500 $\mu \mathrm{M}$ DA for $24 \mathrm{hr}$. Next, the viability of the cells was measured by crystal violet assay. (C) The morphology of the cells was evaluated using an inverted microscope (x100 objective). (a) control; (b) $1 \mathrm{mM}$ of NAC; (c) $10 \mathrm{mM}$ of NAC; (d) $500 \mu \mathrm{M}$ of DA; (e) $1 \mathrm{mM}$ of NAC and $500 \mu \mathrm{M}$ of DA; (f) $10 \mathrm{mM}$ of NAC and $500 \mu \mathrm{M}$ of DA. ${ }^{*} \mathrm{p}<0.05$ (MannWhitney $U$ test). prevented the DA-induced cytotoxicity. The survival rate was found to be greater than $95 \%$ in the presence of $10 \mathrm{mM} \mathrm{NAC} \mathrm{(Fig.} \mathrm{1B).} \mathrm{These} \mathrm{findings} \mathrm{were} \mathrm{con-}$ firmed by microscopic examination (Fig. 1C). Thus, $10 \mathrm{mM}$ NAC was used for subsequent experiments.

Dopamine-induced apoptotic cell death and the effects of NAC. Early events in the apoptotic process include the translocation of phosphatidylserine. Thus, Annexin $\mathrm{V}$ can bind to phosphatidylserine on the surface of cells undergoing apoptosis. ${ }^{13}$ The present study showed that DA treatment produced numerous Annexin- $V$ positive cells, and that NAC effectively prevented the formation of Annexin- $\mathrm{V}$ positive cells (Fig. 2A). In addition, PARP were clearly activated after DA treatment, and NAC prevented this activation of PARP (Fig. 2B, C).

Akt activation after dopamine treatment and the effects of NAC. To investigate the mechanism underlying DA-induced cell death, the changes in Akt were analyzed by western-blotting. As shown in Figure 3A, immediate changes were not observed; however, Akt phosphorylation was slowly increased by time-dependent manner after DA treatment. We also evaluated the effects of NAC to determine if it could inhibit the DA-induced Akt activation. As shown in Figure 3B, NAC clearly inhibited DA-induced Akt activation.

Protective effects of the Akt pathway inhibitor. The role of Akt pathway in the induction of DA-induced cell death was evaluated. Cell viability assay (Fig. 4A) showed that LY294002 partially protected against DA-induced apoptotic cell death. In addition, cell death was evaluated by flow cytometric analysis. After DA treatment, cells were analyzed by forward scattering and side scattering. Results showed that DA treatment induced the appearance of cells (R1) at the right side of normal cells. Thus, these cells are considered to be apoptotic cells. Then, LY294002 was added to test the effects of inhibition of Akt pathway in DA-induced cell death. It was found that probable apoptotic cell death has decreased from $33.5 \%$ to $15.0 \%$ (Fig 4B, C).

Involvement of Akt and Bad in the induction of DA-induced apoptotic cell death. Western blotting demonstrated that the DA induced activation of Bad, while NAC almost completely abolished the DA induced activation of Bad. LY294002 also partially inhibited the DA induced activation of Bad (Fig. 5A). However, Bcl-2 and Bcl-xL were not changed (Fig. 5B, C).

\section{Discussion}

Oxidative stress is believed to be a key mediator of neurotoxicity by DA. The auto-oxidation of DA produces quinines as well as an array of other free 
radical species. Additionally, monoamine oxidase (MAO) contributes to DA toxicity via the generation of hydrogen peroxide and 3,4-dihydroxyphenylacetaldehyde (DOPAL). These ROS and quinines induce cellular damage and apoptosis. ${ }^{14}$ Previously, we reported that DA induced apoptotic cell death in Mel-Ab cells and cultured normal human melanocytes. Furthermore, we showed that thiol-containing compounds, such as NAC and GSH, induced a marked protective effect against apoptosis, while vitamin C, vitamin $\mathrm{E}$, Trolox and quercetin had negligible protective effects. $^{8}$

In the present study, the molecular mechanism of cell death following DA treatment was investigated. The results showed that delayed activation of Akt occurred following DA treatment (Fig. 3). It has previously been reported that phosphotidylinositol 3-kinase regulates melanogenesis by modulating the expression of tyrosinase, and that activation of Akt is related to the suppression of melanin production in G361 melanoma cells. ${ }^{15}$

It has also been reported that Akt is a major mediator of the cell survival pathway; therefore, activation of Akt leads to the inhibition of caspase activity and protection from apoptotic cell death. ${ }^{16}$ Despite this, stimulation of the Fas receptor by its ligand (FasL) induces phosphorylation of Akt and a parallel increase in apoptosis in epidermal CI41 cells. ${ }^{17}$ Furthermore, electron resonance studies have shown that FasL treatment induces rapid generation of reactive oxygen species (ROS), and that inhibition of ROS by antioxidants effectively inhibits Akt signaling. As already indicated, increased Akt is a hallmark of antiapoptotic survival signals. ${ }^{18}$ However, oxidative stress related Akt activation leads to apoptotic cell death. ${ }^{11}$ Taken together, these findings suggest that DA also leads to redox sensitive Akt activation and apoptotic cell death.

In mammals, three Akt isoforms Akt1, Akt2, Akt3 which exhibit sequence homology are known. Akt1 is the most ubiquitously expressed isoform and Akt2 has its highest expression levels in insulin-responsive tissue. ${ }^{1,20}$ Akt3 expression is mainly limited to brain, testis, lung, heart, kidney, mammary gland and fat. ${ }^{21}$ Since, several previous studies showed that Akt1 is involved in apoptosis induced by oxidative stress 11 or in the redox

Figure 3. Activation of Akt after DA treatment. (A) After serum starvation, the cells were treated with $500 \mu \mathrm{M}$ DA for the indicated time points. Total-Akt antibody was used as a control for equal loading of proteins. (B) After serum starvation, the cells were treated with $500 \mu \mathrm{M}$ DA for $16 \mathrm{hr}$ with or without pretreatment with $10 \mathrm{mM}$ for $20 \mathrm{~min}$. Total-Akt antibody was used as a control for equal loading of proteins.

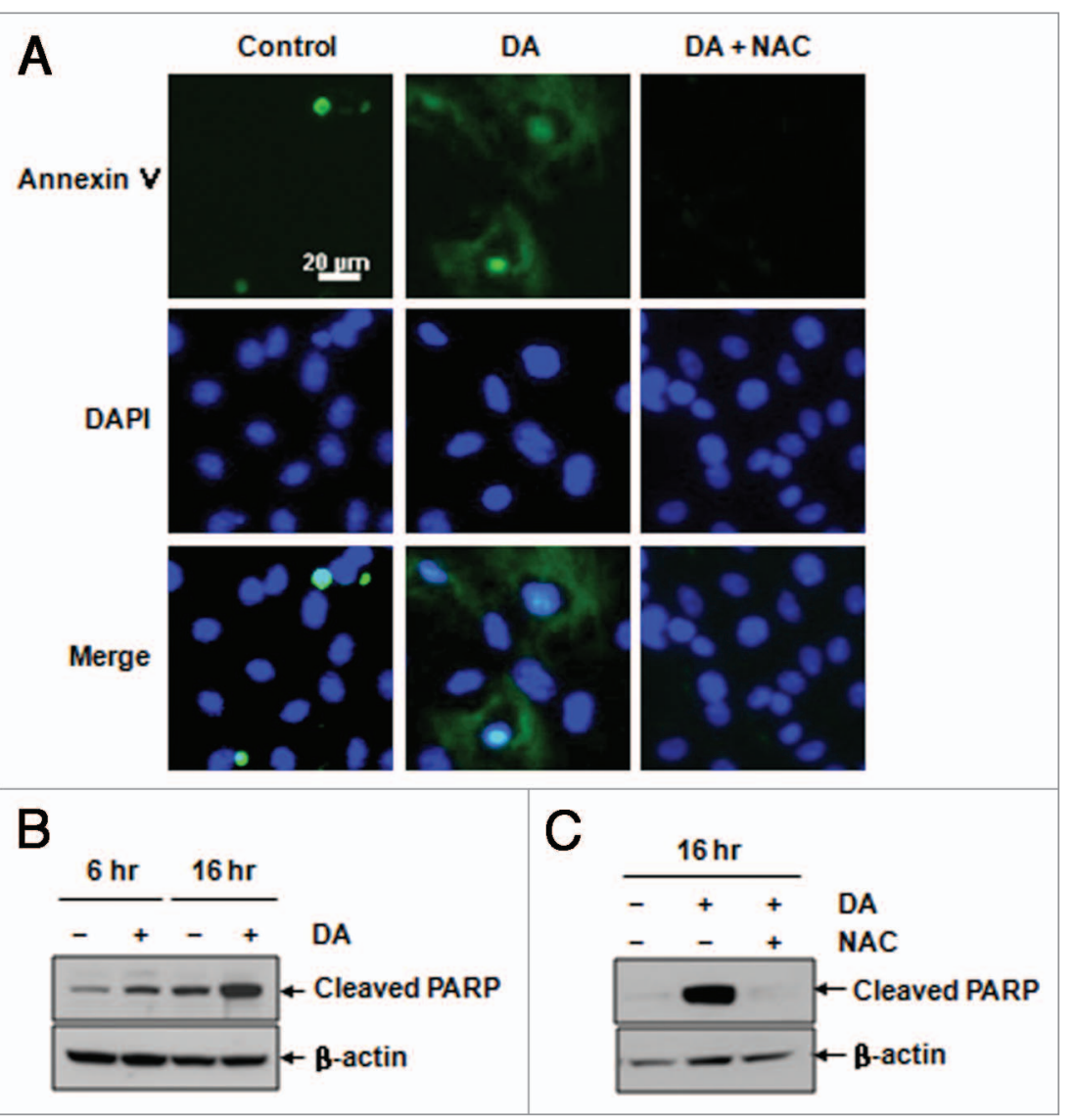

Figure 2. Microscopic observation of DA-induced cell death and PARP activation by western blotting. (A) After serum starvation, the cells were treated with $500 \mu \mathrm{M}$ DA for $16 \mathrm{hr}$ with or without pretreatment with $10 \mathrm{mM}$ NAC for $20 \mathrm{~min}$. Photographs were then taken using a fluorescent inverted microscope (x100 objective). (B) After serum starvation, the cells were treated with $500 \mu \mathrm{M} \mathrm{DA}$ for $6 \mathrm{hr}$ or $16 \mathrm{hr}$. $\beta$-actin antibody was used as a control for equal loading of proteins. (C) The cells were then treated with $500 \mu \mathrm{M}$ DA for $16 \mathrm{hr}$ with or without $10 \mathrm{mM}$ NAC pretreatment. $\beta$-actin antibody was used as a control for equal loading of proteins. 


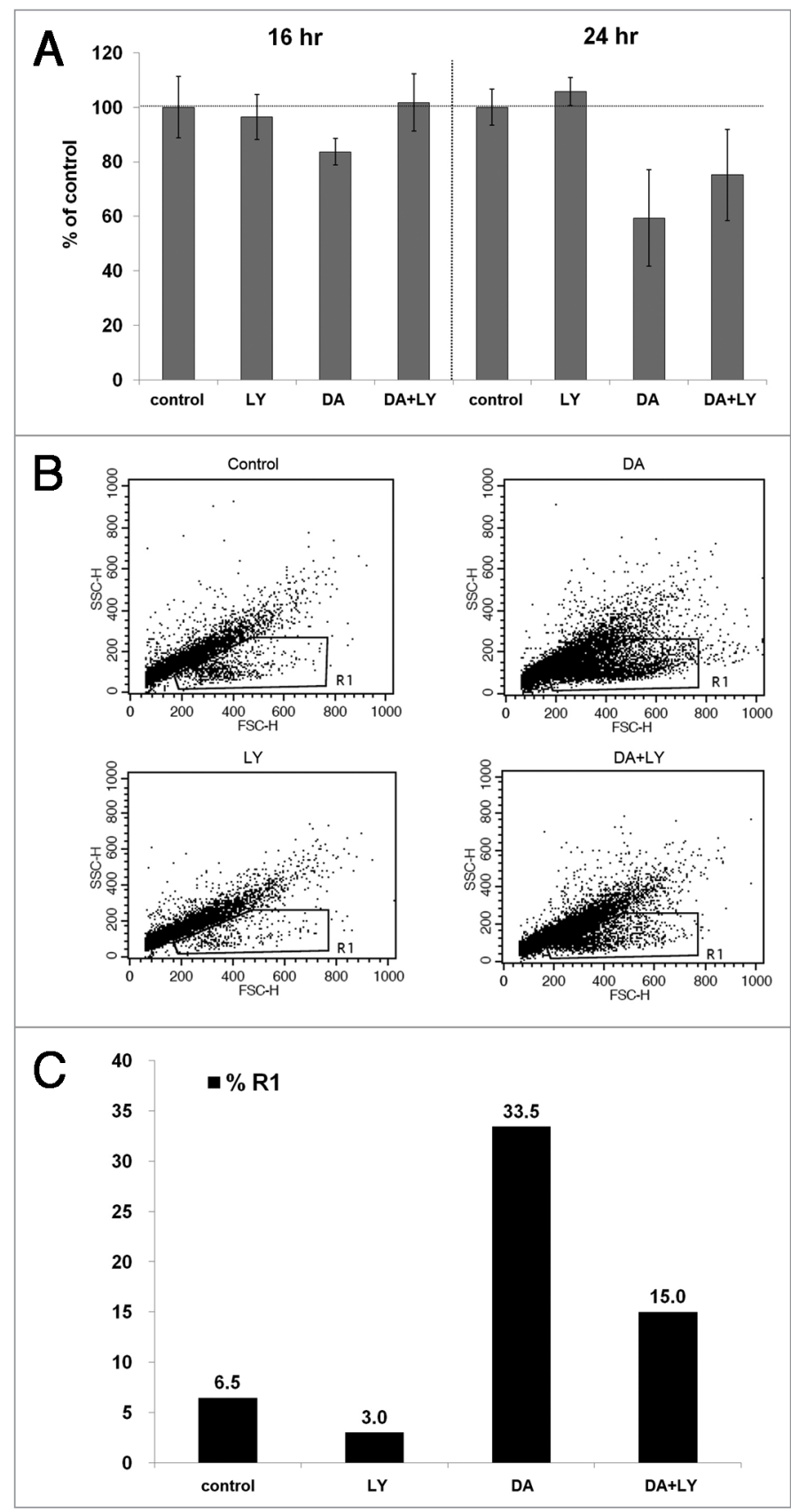

Figure 4. Effect of Akt inhibitor on DA-induced cell death. (A) After serum starvation, the cells were treated with $500 \mu \mathrm{M}$ DA for $16 \mathrm{hr}$ or $24 \mathrm{hr}$ with or without pretreatment with $50 \mu \mathrm{M}$ LY294002 for $20 \mathrm{~min}$. Viability of the cells was measured by crystal violet assay. ${ }^{*} p<0.05$ (Mann-Whitney $U$ test). (B, C) After serum starvation, the cells were treated with $500 \mu \mathrm{M}$ DA for $16 \mathrm{hr}$ with or without pretreatment with $50 \mu \mathrm{M} \mathrm{LY} 294002$ for $20 \mathrm{~min}$. Flow cytometric analyses were measured by forward and side scattering. Graph shows the percentages of representative data among two independent experiments.

modulation of cell cycle progression, ${ }^{22}$ we could presume that the Akt which detected in our study might be Akt1.

To determine whether DA induced apoptotic cell death via the Akt pathway, Mel-Ab cells were treated with DA with or without LY294002 (a specific inhibitor of the Akt pathway)

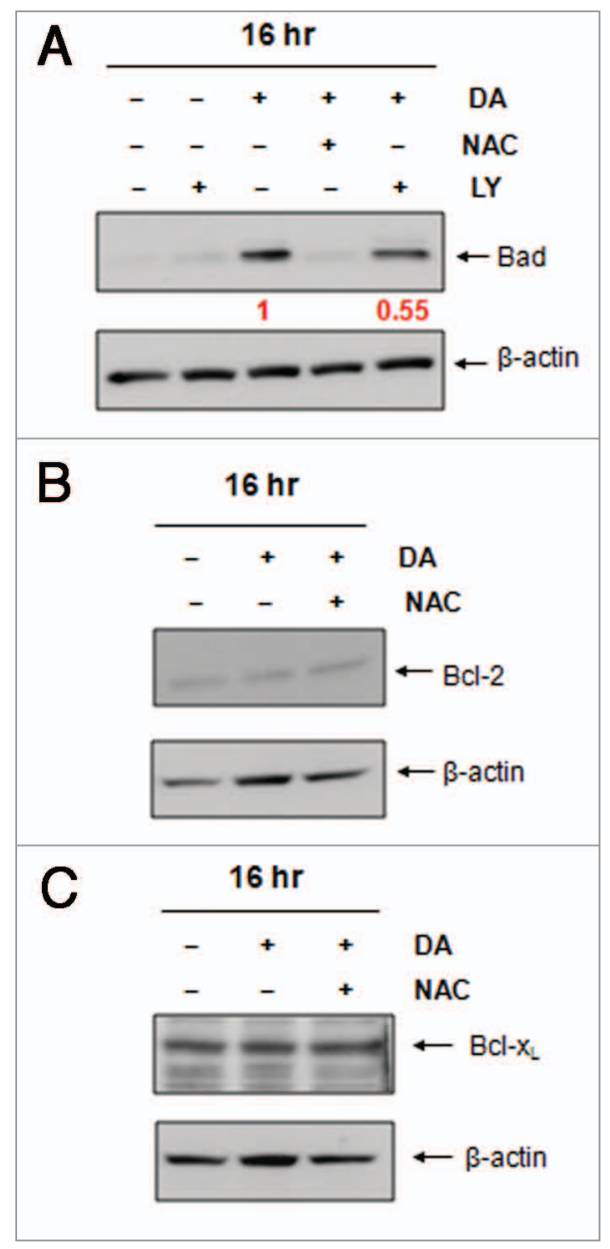

Figure 5. Levels of $\mathrm{Bad}, \mathrm{BCl}-2$ and $\mathrm{BCl}-\mathrm{xL}$ in DA-induced apoptosis. (A) After serum starvation, the cells were treated with $500 \mu \mathrm{M}$ DA for $16 \mathrm{hr}$ with or without pretreatment with $10 \mathrm{mM}$ NAC or $50 \mu \mathrm{M}$ LY294002. $\beta$-actin antibody was used as a control for equal loading of proteins. (B, C) Western blotting was conducted using $\mathrm{Bcl}-2$ (B) or $\mathrm{BCl}-\mathrm{xL}$ (C) antibody. $\beta$-actin antibody was used as a control for the equal loading of proteins.

pretreatment for $20 \mathrm{~min}$. The results revealed that LY294002 partially inhibited the DA-induced cell death (Fig 4, 5). These findings indicate that the Akt pathway is involved in DA-induced cell death. Furthermore, NAC, which effectively protects against DA-induced cell death (Fig. 1), also inhibits DA-induced Akt activation (Fig. 3). Taken together, these findings indicate that DA may induce apoptotic cell death through the activation of Akt, which is considered to be redox sensitive.

It has also been reported that proteins belonging to the $\mathrm{Bcl}-2$ family are important regulators of cell death in mammalian cells. ${ }^{23} \mathrm{Bad}$ is a distinct member of the $\mathrm{Bcl}-2$ family that promotes cell death, at least in part, through heterodimerization with the survival proteins, Bcl-2 and Bcl-xL.24 The proapoptotic function of Bad is reported to be regulated by the Akt pathway. ${ }^{10}$ Recently, it is also reported that Myricetin, a potent anticancer phytochem$\mathrm{ical}$, caused a decrease in phosphorylation of Bad by decreasing phosphorylation of Akt. ${ }^{25}$ Furthermore, it is reported that transforming growth factor-beta prevent osteoblast apoptosis 
via PI3K/Akt and $\mathrm{p}$-Bad signaling. These report showed that cell survival signaling is closely related to PI3K/Akt and p-Bad signaling. ${ }^{26}$ The results of the present study showed that DA increased the levels of Bad, but it had no effect on the levels of Bcl-2 and Bcl-xL (Fig. 6). These results suggest that DA-induced Bad promotes cell death through heterodimerization with Bcl-2 and Bcl-xL.

In conclusion, DA can induce redox-sensitive Akt1 phosphorylation and upregulation of Bad, which may promote melanocyte cell death in vitiligo.

\section{Materials and Methods}

Reagents. Dopamine hydrochloride (DA, H8502) and N-AcetylL-cysteine (NAC, A8199) were purchased from Sigma-Aldrich, Inc. (St. Louis, MO). Antibodies recognizing cleaved PARP (\#9544), Bcl-2 (\#2876), Bad (\#9292), and $\beta$-actin (\#4967) were obtained from Cell Signaling Technology, Inc. (Danvers, MA). Antibodies recognizing phospho-Akt1/2/3 (Ser473, sc-7985-R), total-Akt (sc-8312) and Bcl- $\mathrm{x}_{\mathrm{L}}$ (sc-7195) were obtained from Santa Cruz Biotechnology, Inc. (Santa Cruz, CA). LY294002 (PHZ1144) was purchased from Invitrogen (Carlsbad, CA).

Cell cultures. Mel-Ab cells, a mouse-derived spontaneously immortalized melanocyte cell line that produces large amounts of melanin, ${ }^{12}$ were cultured in Dulbecco's modified Eagle's medium (DMEM) supplemented with 10\% fetal bovine serum (FBS, SH30070.03, Hyclone, Thermo Fisher Scientific Inc., Waltham, MA), $100 \mathrm{nM}$ 12-O-tetradecanoylphorbol-13-acetate (TPA, P8139, Sigma), $1 \mathrm{nM}$ cholera toxin (C8052, Sigma), and $1 \mathrm{x}$ antibiotic-antimycotic (\#15240-062, Invitrogen) at $37^{\circ}$ under $5 \% \mathrm{CO}_{2}$.

Crystal violet assay. Cell viability was determined by a crystal violet assay. ${ }^{12}$ After removal of the culture media, cells were stained with $0.1 \%$ crystal violet in $10 \%$ ethanol for $5 \mathrm{~min}$ at room temperature. The cells were then rinsed five times with distilled water. Next, the crystal violet remaining in the cells was extracted by treatment with $95 \%$ ethanol for $15 \mathrm{~min}$ at room temperature. The absorbance was then determined at $590 \mathrm{~nm}$ using an ELISA reader (Spectra max plus 384, Molecular Devices, Sunnyvale, CA).

Protective effects of antioxidants. To investigate the cytoprotective activity of NAC, Mel-Ab cells were seeded onto 6-well plates $(1 \times 105$ cells/well) or 24 -well plates $(2 \times 104$ cells/well). After serum starvation (DMEM-0.1\% BSA) for $24 \mathrm{hr}$, the cells were pretreated with NAC (1 or $10 \mathrm{mM}$ ) for $20 \mathrm{~min}$. Freshly prepared DA solution $(500 \mu \mathrm{M})$ was then added to each well, after which the samples were incubated for $24 \mathrm{hr}$.

\section{References}

1. Fisher-Wellman K, Bell HK, Bloomer RJ. Oxidative stress and antioxidant defense mechanisms linked to exercise during cardiopulmonary and metabolic disorders. Oxid Med Cell Longev 2009; 2:43-51.

2. Lahaie-Collins V, Bournival J, Plouffe M, Carange J, Martinoli MG. Sesamin modulates tyrosine hydroxylase, superoxide dismutase, catalase, inducible NO synthase and interleukin-6 expression in dopaminergic cells under MPP-induced oxidative stress. Oxid Med Cell Longev 2008; 1:54-62.
Morphological examination. The morphology of the cultured Mel-Ab cells was observed using a fluorescent inverted microscope (Axio Observer. Z1, Carl Zeiss, Thornwood, NY). Morphological changes were evaluated at 100x magnification using the Axio Vision 4.7 software (Carl Zeiss).

Annexin staining. After treatment, the cells were washed using HEPES buffer and then incubated with $2 \%$ Annexin-VFluorescein (\#11 858777 001, Roche, Mannheim, Germany) in HEPES buffer for $15 \mathrm{~min}$ at room temperature. The stained cells were then rinsed with methanol and incubated with $1 \mu \mathrm{g} / \mathrm{ml}$ DAPI (\#10 236276 001, Roche) to counter-stain the nucleus. After washing, the cells were observed using a fluorescent inverted microscope.

Western blot analysis. Cells were lysed in buffer composed of $62.5 \mathrm{mM}$ Tris- $\mathrm{HCl}$ (pH 6.8), $2 \%$ SDS, $5 \% \beta$-mercaptoethanol, $2 \mathrm{mM}$ phenylmethylsulfonyl fluoride, $1 \mathrm{mM} \mathrm{Na} 3 \mathrm{VO} 4,50 \mathrm{mM}$ $\mathrm{NaF}$ and protease inhibitors (Roche). The total protein concentration was determined using a Bio-Rad protein assay kit (Bio-Rad, Hercules, CA), after which $50 \mu \mathrm{g}$ of proteins were electrophoresed using Tris-Glycine gel (EC6008, Invitrogen). The separated proteins were then transferred to a PVDF membrane (Immobilon-P, IPVH00010, Millipore, Bedford, MA). The membrane was then blocked using $5 \%$ non-fat dry milk (Bio-Rad) in Tris-buffered Saline containing $0.2 \%$ Tween 20. Next, the blocked membrane was incubated with primary antibody and horseradish peroxidase-conjugated secondary antibody. The bound antibodies were detected using an ECL western blotting analysis system (RPN2109, Amersham International, Little Chalfont, UK).

Flow cytometric analysis. Sixteen hours after DA treatment, we collected the culture supernatant, which contained floating dying cells and apoptotic cells. Then adherent cells were harvested by a brief trypsinization. The two fractions were combined and washed with PBS. Flow cytometric analyses were performed on a FACSCalibur (Becton Dickinson, San Jose, CA). Experiments were repeated at least twice under the same conditions and settings. The effects of LY294002 $(50 \mu \mathrm{M})$ pretreatment were also investigated.

Statistics. Differences between groups were analyzed by a Mann-Whitney U test. The SPSS statistics package (SPSS V12.0K, SPSS Inc., Chicago, IL) was used for all analyses.

\section{Acknowledgements}

This study was supported by a grant from the Korea Healthcare Technology R\&D Project, Ministry for Health, Welfare \& Family Affairs, Republic of Korea (A084379). We also thank the Welskin Corporation for their support.
3. Blum D, Torch S, Lambeng N, Nissou M, Benabid AL, Sadoul R, et al. Molecular pathways involved in the neurotoxicity of 6-OHDA, dopamine and MPTP: contribution to the apoptotic theory in Parkinson's disease. Prog Neurobiol 2001; 65;135-72.

4. Pedrosa R, Soares-da-Silva P. Oxidative and nonoxidative mechanisms of neuronal cell death and apoptosis by L-3,4-dihydroxyphenylalanine (L-DOPA) and dopamine. Br J Pharmacol 2002; 137:1305-13.
5. Cucchi ML, Frattini P, Santagostino G, Orecchia G. Higher plasma catecholamine and metabolite levels in the early phase of nonsegmental vitiligo. Pigment Cell Res 2000; 13:28-32.

6. Cucchi ML, Frattini P, Santagostino G, Preda S, Orecchia G. Catecholamines increase in the urine of non-segmental vitiligo especially during its active phase. Pigment Cell Res 2003; 16:111-6.

7. Morrone A, Picardo M, de Luca C, Terminali O, Passi S, Ippolito F. Catecholamines and vitiligo. Pigment Cell Res 1992; 5:65-9. 
8. Park ES, Kim SY, Na JI, Ryu HS, Youn SW, Kim DS, et al. Glutathione prevented dopamine-induced apoptosis of melanocytes and its signaling. J Dermatol Sci 2007; 47:141-9.

9. Kauffmann-Zeh A, Rodriguez-Viciana P, Ulrich E, Gilbert C, Coffer P, Downward J, et al. Suppression of c-Myc-induced apoptosis by Ras signalling through PI(3)K and PKB. Nature 1997; 385:544-8.

10. del Peso L, Gonzalez-Garcia M, Page C, Herrera R, Nunez G. Interleukin-3-induced phosphorylation of BAD through the protein kinase Akt. Science 1997; 278:687-9.

11. van Gorp AG, Pomeranz KM, Birkenkamp KU, Hui RC, Lam EW, Coffer PJ. Chronic protein kinase B (PKB/c-Akt) activation leads to apoptosis induced by oxidative stress-mediated Foxo3a transcriptional upregulation. Cancer Res 2006; 66:10760-9.

12. Dooley TP, Gadwood RC, Kilgore K, Thomasco LM. Development of an in vitro primary screen for skin depigmentation and antimelanoma agents. Skin Pharmacol 1994; 7:188-200.

13. Vermes I, Haanen C, Steffens-Nakken $\mathrm{H}$, Reutelingsperger C. A novel assay for apoptosis. Flow cytometric detection of phosphatidylserine expression on early apoptotic cells using fluorescein labelled Annexin V. J Immunol Methods 1995; 184:39-51.

14. LaVoie MJ, Hastings TG. Dopamine quinone formation and protein modification associated with the striatal neurotoxicity of methamphetamine: evidence against a role for extracellular dopamine. J Neurosci 1999; 19:1484-91.
15. Oka M, Nagai H, Ando H, Fukunaga M, Matsumura $\mathrm{M}$, Araki K, et al. Regulation of melanogenesis through phosphatidylinositol 3-kinase-Akt pathway in human G361 melanoma cells. J Invest Dermatol 2000; 115:699-703.

16. Ahmed NN, Grimes HL, Bellacosa A, Chan TO, Tsichlis PN. Transduction of interleukin-2 antiapoptotic and proliferative signals via Akt protein kinase. Proc Natl Acad Sci U S A 1997; 94:3627-32.

17. Lu B, Wang L, Stehlik C, Medan D, Huang C, Hu $\mathrm{S}$, et al. Phosphatidylinositol 3-kinase/Akt positively regulates Fas (CD95)-mediated apoptosis in epidermal Cl41 cells. J Immunol 2006; 176:6785-93.

18. Coffer PJ, Jin J, Woodgett JR. Protein kinase B (c-Akt): a multifunctional mediator of phosphatidylinositol 3-kinase activation. Biochem J 1998; 335:1-13.

19. Cho H, Thorvaldsen JL, Chu Q, Feng F, Birnbaum MJ. Akt1/PKBalpha is required for normal growth but dispensable for maintenance of glucose homeostasis in mice. J Biol Chem 2001; 276: 38349-52

20. Cho H, Mu J, Kim JK, Thorvaldsen JL, Chu Q, Crenshaw EB 3rd, et al. Insulin resistance and a diabetes mellitus-like syndrome in mice lacking the protein kinase Akt2 (PKB beta). Science 2001; 292:1728-31.

21. Masure S, Haefner B, Wesselink JJ, Hoefnagel E, Mortier E, Verhasselt P, et al. Molecular cloning, expression and characterization of the human serine/threonine kinase Akt-3. Eur J Biochem 1999; 265:353-60.
22. Antico Arciuch VG, Galli S, Franco MC, Lam PY, Cadenas E, Carreras MC, et al. Akt1 intramitochondrial cycling is a crucial step in the redox modulation of cell cycle progression. PLoS One 2009; 4:e7523.

23. White E. Life, death, and the pursuit of apoptosis. Genes Dev 1996; 10:1-15.

24. Yang E, Zha J, Jockel J, Boise LH, Thompson CB, Korsmeyer SJ. Bad, a heterodimeric partner for $\mathrm{Bcl}-\mathrm{xL}$ and $\mathrm{Bcl}-2$, displaces $\mathrm{Bax}$ and promotes cell death. Cell 1995; 80:285-91.

25. Kim W, Yang HJ, Youn H, Yun YJ, Seong KM, Youn B. Myricetin Inhibits Akt Survival Signaling and Induces Bad-mediated Apoptosis in a Low Dose Ultraviolet (UV)-B-irradiated $\mathrm{HaCaT}$ Human Immortalized Keratinocytes. J Radiat Res 2010; In press.

26. Dufour C, Holy X, Marie PJ. Transforming growth factor-beta prevents osteoblast apoptosis induced by skeletal unloading via PI3K/Akt, Bcl-2, and phosphoBad signaling. Am J Physiol Endocrinal Metab 2008; 294:794-801. 


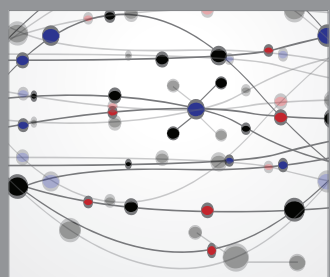

The Scientific World Journal
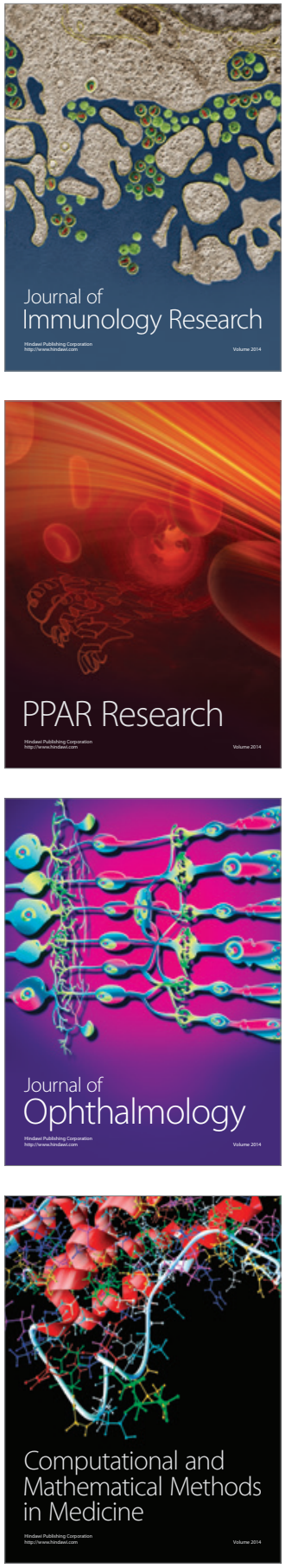

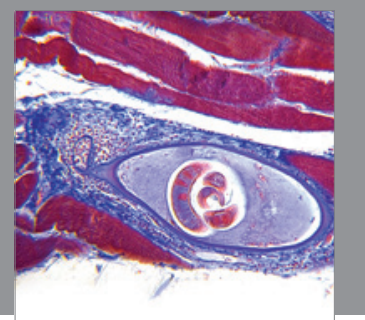

Gastroenterology

Research and Practice
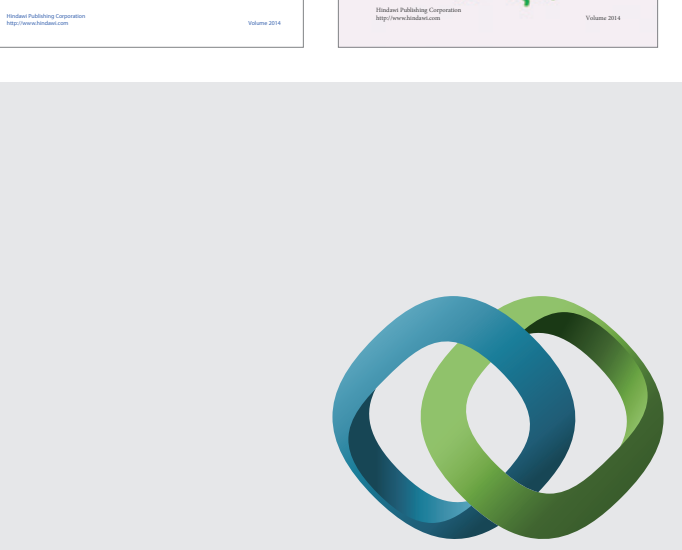

\section{Hindawi}

Submit your manuscripts at

http://www.hindawi.com
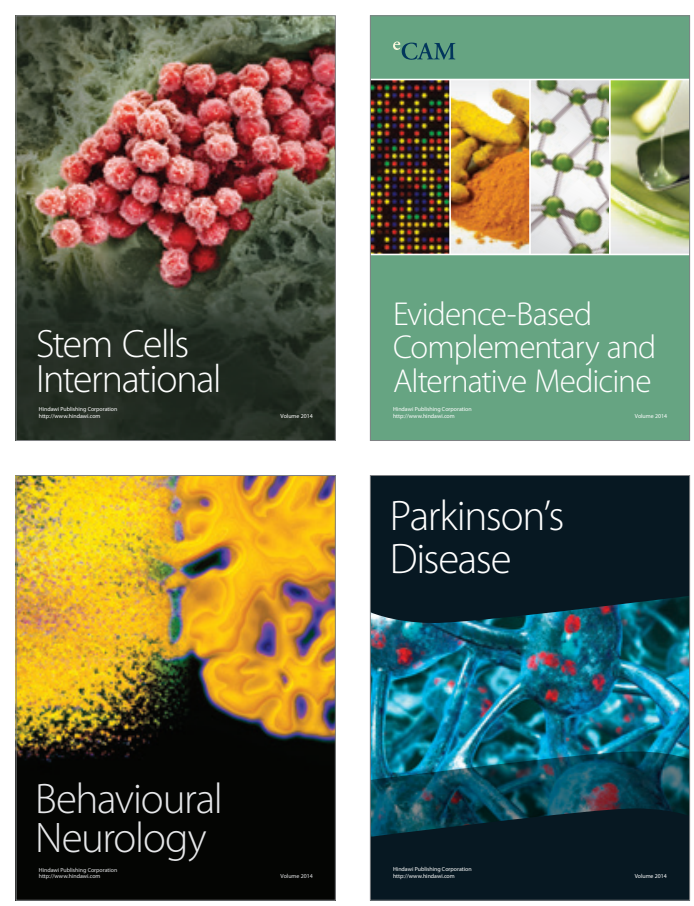

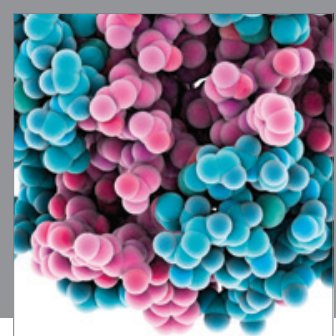

Journal of
Diabetes Research

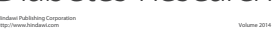

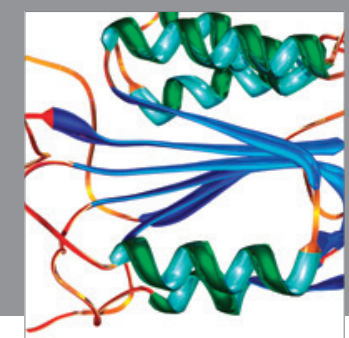

Disease Markers
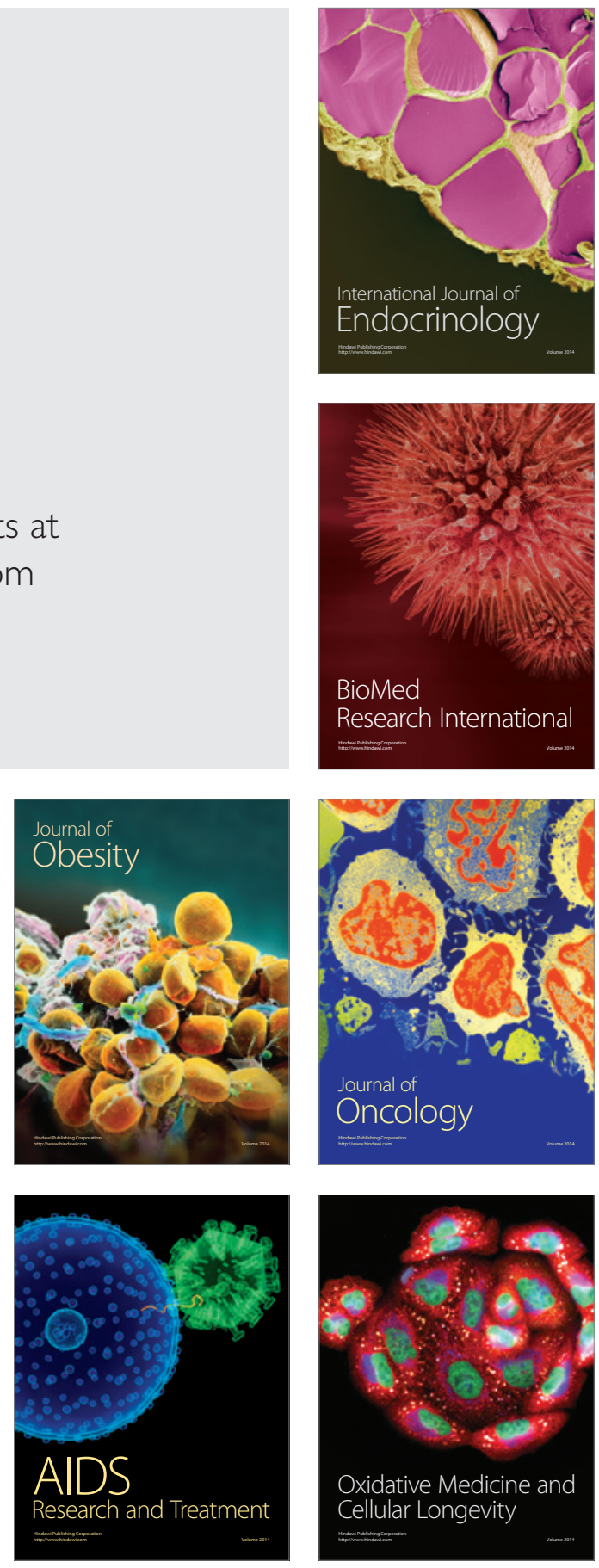